\title{
EFEITO DO PROCESSAMENTO NA COMPOSIÇÃO DE VOLÁTEIS DE SUCO CLARIFICADO DE MAÇÃ FUJI ${ }^{1}$
}

\author{
Natália S. JANZANTTI ${ }^{2}$, Maria Regina B. FRANCO ${ }^{2, *}$, Gilvan WOSIACKI ${ }^{3}$
}

\begin{abstract}
RESUMO
Os compostos voláteis são responsáveis pelo sabor característico dos alimentos, são termolábeis e também facilmente perdidos ou modificados durante o processamento. Este estudo teve como objetivo verificar o efeito do processamento na composição de voláteis do suco clarificado de maçãs Fuji. O isolamento dos voláteis foi feito por enriquecimento do "headspace" em polímero poroso e eluição com hexano. Oitenta e quatro compostos voláteis foram detectados na maçã Fuji, por cromatografia gasosa de alta resolução, dos quais 30 foram identificados por espectrometria de massas, aliada aos indices de Kovats. A classe quimica predominante na maçã Fuji, dentre os compostos identificados, foi a dos ésteres, compreendendo ao todo 28 voláteis. Os compostos majoritários na fruta foram $\alpha$-farneseno, acetato de 2-metil butila, acetato de butila e acetato de hexila. Após a prensagem, o aldeído hexanal aumentou drasticamente e se tornou majoritário. A clarificação foi a etapa que menos causou modificações na composição de voláteis, mantendo o aldeído como majoritário. A pasteurização foi a etapa critica do processamento, como esperado. Nesta etapa, além de ocorrer a diminuição da área de todos os componentes voláteis, ocorreu a perda total do éster octanoato de isoamila e de 15 compostos não identificados. No entanto, os compostos voláteis majoritários após a prensagem e em todas as etapas do processamento foram os mesmos: acetato de butila, acetato de 2-metil butila, acetato de hexila e um composto não identificado.

Palavras-chave: cromatografia gasosa; compostos voláteis; suco clarificado de maçã.
\end{abstract}

\section{SUMMARY}

EFFECT OF PROCESSING ON THE VOLATILE COMPOSITION OF THE CLARIFIED FUJI APPLE JUICE. Volatile compounds are responsible for food's aroma and flavor. Since they are thermolabile compounds, any increase in temperature can result in modification and/or losses during processing. The objective of this work was to verify changes in the volatile composition of apples, cultivar Fuji, during the processing of clarified juice. Headspace volatile compounds of fruit and juice samples were trapped on porous polymer and eluted with hexane. Eighty-four volatile compounds were detected in the Fuji apple by high resolution gas chromatography, of which thirty compounds were identified by GC-MS and Kovats indices. The predominant class of compounds was that of esters, of which 28 compounds were identified. Butyl acetate, 2-methyl butyl acetate, hexyl acetate and $\propto$-farnesene were the major volatiles in the fresh fruit. Hexanal was the major volatile after pressing. Pasteurization of the clarified juice was the processing step that caused the most drastic change in the volatile composition, all the peak areas in the chromatogram being reduced. However, the major volatile compounds after pressing and during all the processing steps were the same as in the juice samples: hexanal, butyl acetate, hexyl acetate, 2-methyl butyl acetate and a non-identified compound.

Keywords: gas chromatography; volatile compounds; apple clarified juice.

\section{1 - INTRODUÇÃO}

A produção brasileira de maçãs alcançou mais de 900 mil toneladas em 2000 e está localizada nos estados de Santa Catarina, Rio Grande do Sul e Paraná. Com o fenômeno de super-abastecimento, a solução encontrada pelos produtores foi aumentar a exportação da fruta in natura e a venda para as fábricas de suco.

A maçã brasileira é um produto bem apreciado pelo mercado europeu, em razão de sua qualidade e também pela época diferente de sua colheita. As variedades de maçãs mais cultivadas são a Gala (46\%), a Fuji (45\%) e a Golden (6\%). No ano de 2000, o Brasil exportou para a Europa, via Holanda principalmente, mais de 60 mil toneladas de maçã. Entre fruta in natura e suco, a maçã já agrega mais de US\$30 milhões anuais à receita cambial

\footnotetext{
Recebido para publicação em 03/12/2002. Aceito para publicação em 12/06/2003 (001020).

2Departamento de Ciência de Alimentos/Faculdade de Engenharia de Alimentos/UNICAMP-. C.P. 6121, CEP 13081-970, Campinas-SP. franco@fea.unicamp.br

${ }^{3}$ Departamento de Zootecnia e Tecnologia de Alimentos, Setor de Ciências Agrárias e de Tecnologia da UEPG. Praça Santos Andrade s/n, Centro. CEP 84010-330, Ponta Grossa, PR

* A quem a correspondência deve ser enviada.
}

brasileira, segundo a Associação Brasileira dos Produtores de Maçã [1].

Os produtores entregaram em 2000, mais de $15 \%$ da produção para os fabricantes de suco, com previsão de aumento para a safra de 2001. A maior parte do suco de maçã destina-se à exportação. Dependendo do uso final, o suco de maçã pode ser clarificado e depois concentrado em evaporador para ser transportado a granel.

Sucos clarificados de maçãs de diferentes variedades (incluindo a Fuji), obtidos em laboratório segundo o procedimento industrial, já foram avaliados quanto à estabilidade, parâmetros físico-químicos, aceitação de mercado e características sensoriais de aparência e sabor, além da avaliação microbiológica [15, 16, 17].

Este suco clarificado é simplesmente o produto da extração da fruta, totalmente natural, sem conservantes e sem adição de açúcar ou adoçante para a correção do sabor. O produto se apresenta como um liquido claro, limpido, brilhante e o gosto doce é da própria fruta.

A qualidade do suco de maçã vai depender das características do sabor da fruta. O sabor, por sua vez, é uma resposta integrada do gosto (doce, amargo, ácido, salgado e umami) e do aroma, sendo este dado pela presença de numerosos compostos voláteis. São muitos os 
fatores que afetam a composição e concentração desses compostos voláteis: fatores ambientais, variedade e grau de maturação da matéria-prima, etapas do processamento (prensagem, tratamento enzimático, clarificação e tratamentos térmicos) e condições de armazenamento [10].

As diferentes etapas do processamento podem causar mudanças no perfil do aroma do produto final quando comparado com a fruta fresca. Alguns autores [2, 8, 12]estudaram mudanças na composição de voláteis durante o processamento do suco de maçãs.

PÉREDI et al. [12] observaram as modificações ocorridas após cada etapa do processamento do suco de maçã, em duas fábricas da Hungria; porém, a cultivar não foi especificada. O processamento empregado foi prensagem, clarificação por tratamento enzimático, filtração e concentração do suco. O tratamento térmico foi a etapa que mais afetou a composição, causando perda qualitativa e quantitativa dos compostos voláteis. Convém ressaltar que os autores empregaram destilação a vapor no preparo da amostra, o que poderia levar à formação de artefatos, e portanto, não adequado para o estudo do efeito do processamento.

DI CESARI et. al. [2] observaram as mudanças na composição de voláteis de maçãs Golden Delicious durante o processamento. Hexanol, hexanal e trans-2-hexanal foram os compostos majoritários em todas as etapas do processamento. Ocorreu a diminuição de todos os compostos durante o processamento, principalmente após o tratamento térmico. A produção de $\mathrm{C}_{6}$ aldeídos a partir de ácidos graxos e a redução de aldeídos para álcoois ocorre rapidamente após a cominuição, segundo os autores. A extração do aroma do suco foi feita por destilação e posterior adsorção dos compostos voláteis em resina apolar de adsorção e eluição com éter etílico.

O único trabalho encontrado na literatura com maçã Fuji foi o de KAKIUCHI et al. [8], que observaram as modificações nos componentes voláteis desta cultivar com o suco obtido após a pasteurização $\left(93^{\circ} \mathrm{C}\right.$ por 30 segundos $)$. Estes pesquisadores utilizaram um método de isolamento dos voláteis que empregava destilação à pressão reduzida a $35^{\circ} \mathrm{C}$ por 6 horas, seguida da extração do destilado aquoso com éter etilico, desidratação do extrato etéreo com $\mathrm{MgSO}_{4}$, evaporação em rotaevaporador e dissolução do resíduo em hexano. Houve o emprego de calor por tempo prolongado, além de muita manipulação da amostra.

O presente trabalho teve como objetivo verificar como cada etapa do processamento de suco clarificado de maçã Fuji pode afetar os compostos do aroma, bem como contribuir na melhoria da qualidade do aroma do suco. Foi utilizado neste caso, um método de "headspace" dinâmico, que não emprega calor e relacionado diretamente ao aroma do produto.

\section{2 - MATERIAL E MÉTODOS}

\section{1 - Seleção da matéria-prima}

Foram utilizadas maçãs da cultivar Fuji procedentes do Estado de Santa Catarina, região de Fraiburgo, adquiridas na CEASA de Campinas. As maçãs estavam em estágio adequado de maturação, de acordo com a aparência.

Estudou-se a safra de 1994 e empregaram-se 72kg de maçãs, que foram divididas em 4 lotes, sendo 3 lotes de $20 \mathrm{~kg}$ empregados para o processamento do suco (em triplicata) e os $12 \mathrm{~kg}$ restantes empregados para a análise dos voláteis da fruta in natura, também em triplicata. Os 3 lotes foram processados em 3 dias consecutivos.

\section{2 - Obtenção do suco}

As maçãs Fuji foram utilizadas para a obtenção do suco clarificado, em processo a nivel laboratorial, fundamentado nas linhas de processamento industrial [16]. As frutas, após lavagem em água corrente, foram selecionadas, retirando-se o pêndulo, miolo (região carpelar) e partes injuriadas. A cominuição foi feita em multi-processador com o acessório ralador e a prensagem em prensa de rosca sem fim, modelo Bertuzzi, com peneira de extração de $0,5 \mathrm{~mm}$. O suco prensado foi transferido para balões de $3 \mathrm{~L}$ e adicionou-se enzimas pectinoliticas (Pectinem Ultra spl, Enzima Novo Nordisk Ferment Ltda.), de acordo com a recomendação do fabricante. Os balões permaneceram por $1 \mathrm{~h}$ em banho-maria a $40^{\circ} \mathrm{C}$, temperatura ótima para a atividade da enzima [13]. Após a despectinização, fezse uma filtração para balões de $3 \mathrm{~L}$ e ao suco obtido realizou-se a clarificação com sistema bentonita-gelatina, à proporção de $50 \mathrm{~g} / \mathrm{hL}$ e de $7 \mathrm{~g} / \mathrm{hL}$ de suco, respectivamente, permanecendo por $2 \mathrm{~h}$ em geladeira. Após esta etapa foi realizada uma nova filtração. O suco assim obtido foi envasado em garrafas âmbar de $600 \mathrm{~mL}$ e, após vedação, foi submetido a um tratamento térmico em banho-maria por $20 \mathrm{~min}$ a $80^{\circ} \mathrm{C}$, com rápido resfriamento posterior até a temperatura ambiente.

Os sucos obtidos após a prensagem, a clarificação e a pasteurização foram analisados cromatograficamente e denominados como suco prensado, suco clarificado e suco pasteurizado, respectivamente.

\section{3 - Preparo da amostra}

Para o isolamento de voláteis das frutas in natura e dos sucos obtidos nas diferentes etapas do processamento (suco prensado, suco clarificado e suco pasteurizado) empregou-se trezentos gramas de amostra acondicionada no balão do sistema de coleta de voláteis. Para o isolamento da fruta e dos sucos prensado e clarificado adicionou-se $\mathrm{NaCl}$ p. a. $30 \%(\mathrm{p} / \mathrm{p})$ para inibição enzimática [4].

\section{4 - Isolamento dos compostos voláteis}

O isolamento dos voláteis foi realizado pelo método de enriquecimento dos vapores do "headspace" em polimero poroso Porapak Q por sucção, conforme descrito por FRANCO \& RODRIGUEZ-AMAYA [4].

Em estudo realizado anteriormente [5], a avaliação sensorial em conjunto com a análise cromatográfica dos extratos permitiu a padronização das condições ótimas 
para a obtenção de um isolado com o aroma original do produto investigado. Os voláteis do "headspace" de maçãs Fuji e dos diferentes sucos obtidos durante o processamento foram coletados por 2 horas em Porapak Q e eluídos com $300 \mu \mathrm{L}$ de hexano grau cromatográfico.

\section{5 - Cromatografia gasosa de alta resolução}

A separação e a detecção dos compostos voláteis foram realizadas em cromatógrafo a gás Varian, modelo 3300, com detector de ionização de chama, injetor tipo splitless e coluna capilar de sílica fundida de fase liquida SE-54 de $50 \mathrm{~m}$ de comprimento, 0,21 $\mathrm{mm}$ de diâmetro interno, a 20psi.

As condições cromatográficas foram: gás de arraste, hidrogênio, com velocidade linear de $45 \mathrm{~cm} / \mathrm{s}$; "make-up", nitrogênio, com fluxo de $30 \mathrm{~mL} / \mathrm{min}$; fluxo de hidrogênio e de ar no detector de $30 \mathrm{~mL} / \mathrm{min}$ e de $300 \mathrm{~mL} / \mathrm{min}$, respectivamente; temperatura do detector de $250^{\circ} \mathrm{C}$; temperatura do injetor de $200^{\circ} \mathrm{C}$; volume injetado de $2 \mu \mathrm{L}$; programação da coluna de $50^{\circ} \mathrm{C}$ por $10 \mathrm{~min}, 2^{\circ} \mathrm{C} / \mathrm{min}$ até $75^{\circ} \mathrm{C}, 3^{\circ} \mathrm{C} / \mathrm{min}$ até $150^{\circ} \mathrm{C}$ e $5^{\circ} \mathrm{C} / \mathrm{min}$ até $200^{\circ} \mathrm{C}$.

Os dados sobre tempos de retenção e as porcentagens relativas dos compostos voláteis foram obtidos através de um integrador Varian, modelo 4290, acoplado ao cromatógrafo. A quantificação foi feita por normalização.

\section{6 - Identificação dos compostos voláteis}

Os compostos voláteis foram identificados por espectrometria de massas e indices de Kovats.

\subsection{1 - Espectrometria de massas}

Foi utilizado cromatógrafo a gás Hewlet-Packard modelo 5890, acoplado a um espectrômetro de massas HP-MSD-5970. A separação foi feita em coluna de sílica fundida LM5, de $30 \mathrm{~m}$ e $0,25 \mathrm{~mm}$ de diâmetro interno, nas mesmas condições utilizadas anteriormente (item 2.5). Os parâmetros foram os seguintes: gás de arraste, hélio ultra puro, com velocidade linear de $32 \mathrm{~cm} / \mathrm{seg}$; temperatura injetor de $250^{\circ} \mathrm{C}$; temperatura detector de $280^{\circ} \mathrm{C}$; fonte de impacto de elétrons de $70 \mathrm{eV}$; injetor split a uma razão de divisão de 1:20; volume injetado de $3 \mathrm{~mL}$. $\mathrm{O}$ analisador utilizado foi o quadrupolo e integrador HP 9133. Os espectros de massas obtidos foram comparados com os da literatura [14].

\subsection{2 - Índice de Kovats}

Foi empregada uma mistura de padrões de alcanos $\mathrm{C}_{8}-\mathrm{C}_{16}$ adicionada à solução dos voláteis, sendo injetado $2 \mathrm{~mL}$ no cromatógrafo gasoso nas mesmas condições das análises cromatográficas. Os indices dos diferentes compostos foram determinados e comparados com os descritos na literatura de acordo com JENNINGS \& SHIBAMOTO [7].

\section{3 - RESULTADOS E DISCUSSÃO}

Durante a safra de 1994, foram detectados 84 componentes voláteis na maçã Fuji por cromatografia gaso- sa de alta eficiência e trinta compostos foram identificados por espectrometria de massas, aliada aos indices de Kovats [6]. O indice de Kovats é um indice de retenção que descreve o comportamento de retenção do composto comparativamente ao de uma mistura de alcanos de diferentes números de átomos de carbono. Este indice de retenção fornece informação sobre a seqüência de eluição do composto e varia em função da fase estacionária e da temperatura, sendo independente das condições experimentais.

Os compostos voláteis identificados compreenderam aproximadamente $97 \%$ da área relativa e já tinham sido relatados como componentes voláteis de maçã [3, 8]. Durante o processamento não ocorreu a formação de novos compostos voláteis. As mudanças observadas na composição de voláteis foram quantitativas.

A maçã Fuji caracterizou-se por uma elevada quantidade de ésteres, compreendendo aproximadamente $68 \%$ da área relativa. Os compostos voláteis majoritários na maçã foram os ésteres acetato de 2-metil butila, acetato de butila e acetato de hexila e o hidrocarboneto sesquiterpeno $\alpha$-farneseno, que juntos, contribuíram com aproximadamente $71 \%$ da área relativa. Um outro componente não identificado (pico 70) também apresentou alta porcentagem relativa (17\%), porém em apenas uma amostra da safra de 1994, enquanto nas outras duas, ele não foi detectado [6].

Outros compostos voláteis encontrados na maçã Fuji foram o aldeído hexanal, além dos ésteres butanoato de metila, acetato de isobutila, 2 -metil butanoato de metila, butanoato de etila, propionato de propila, 2-metil butanoato de etila, butanoato de propila, valerato de etila, propionato de butila, acetato de amila, hexanoato de metila, 2-metil butanoato de propila, butanoato de butila, hexanoato de etila, acetato de ciclo hexila, 2-metil butanoato de butila, hexanoato de propila, propanoato de hexila, 2-metil butanoato de amila, hexanoato de butila, butanoato de hexila, 2-metil butanoato de hexila, hexanoato de isoamila, hexanoato de hexila e octanoato de isoamila.

Os cromatogramas típicos dos compostos voláteis da maçã e das diferentes etapas do processamento estão apresentados na Figura 1.

A Tabela 1 mostra o efeito do processamento do suco de maçã na composição de voláteis. Além da porcentagem relativa média (referente aos 3 lotes analisados), as áreas dos picos também foram incluídas na Tabela 1, para fins de comparação com as outras etapas do processamento, já que durante a pasteurização houve diminuição do número de compostos voláteis, dificultando assim a comparação em termos de porcentagem de área. Houve uma boa repetibilidade das análises em todas as etapas do processamento, apesar de terem sido feitas em 3 dias consecutivos. Não foram incluídos nesta tabela compostos voláteis não identificados, que estavam presentes na amostra em quantidades traços e que atingiram no máximo $0,1 \%$ de área relativa. 


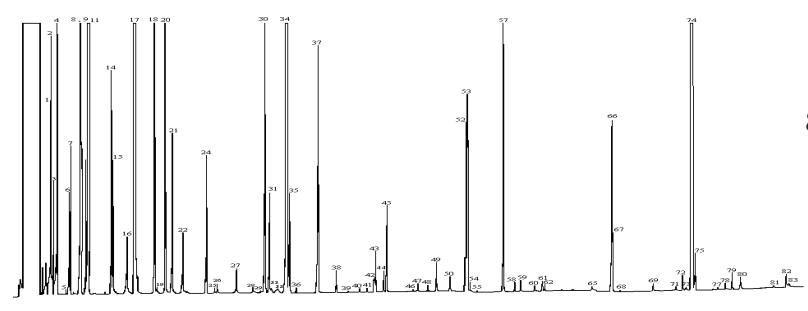

a)
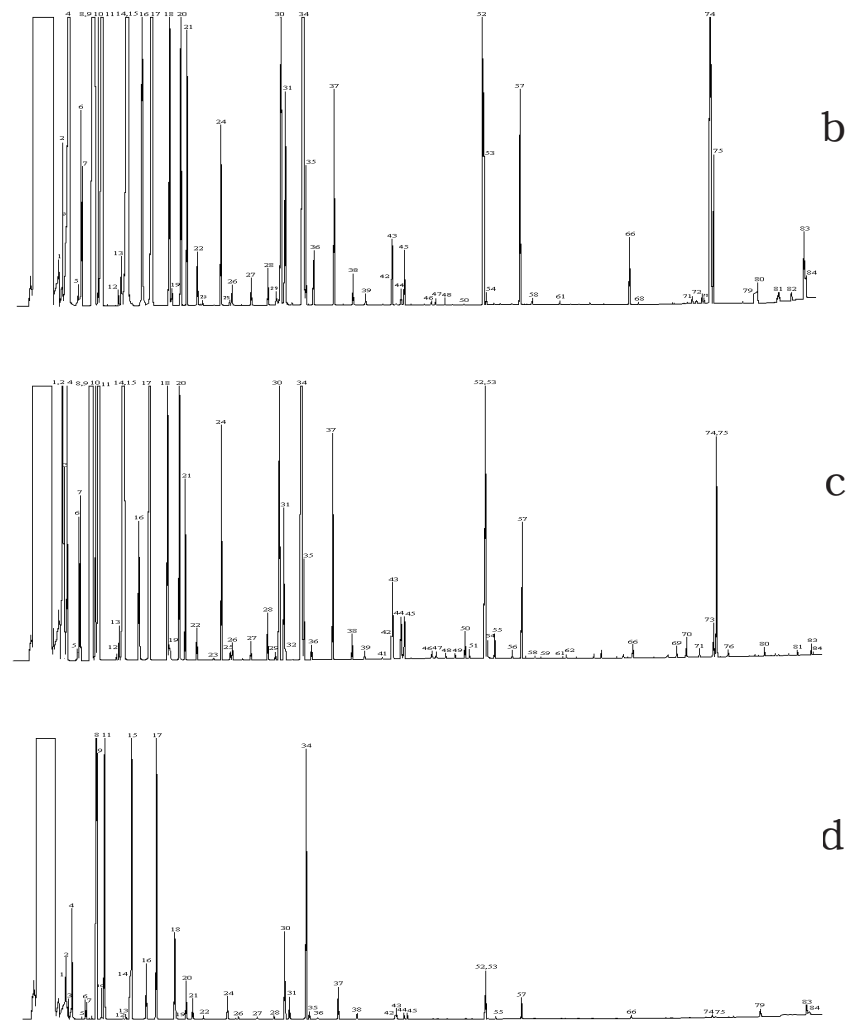

FIGURA 1. Cromatogramas dos compostos voláteis da maçã Fuji: a) fruta, b) suco prensado, c) suco clarificado e d) suco pasteurizado.

De uma maneira geral, observou-se poucas modificações na composição de voláteis durante a prensagem. Algumas das mudanças ocorridas nesta etapa, provavelmente podem ser explicadas pela ação de enzimas, pois a ruptura dos tecidos durante a prensagem permite um maior contato com o substrato [2, 3, 12].

Dentre as modificações que ocorreram nesta etapa, o hexanal aumentou marcantemente, passando de uma porcentagem relativa de $2 \%$ para $40 \%$, tornando-se o componente mais abundante. Os aldeídos $\mathrm{C}_{6}$ são produzidos por reações enzimáticas, quando ocorre a ruptura da estrutura celular. Estes aldeídos estão presentes em larga quantidade em sucos recém-prensados e em pequenas quantidades nas frutas intactas. O hexanal, produto de biodegradação dos lipideos, apresenta um conhecido e característico aroma de "maçã verde" $[3,11]$. $O$ hidrocarboneto sesquiterpeno, $\alpha$-farneseno, diminuiu drasticamente de $21 \%$ para $3 \%$. Um composto volátil não identificado (pico 15) aumentou de $0,5 \%$ para $8,4 \%$ e o acetato de hexila diminuiu de $11 \%$ para $6,5 \%$. Conside- rando o aumento drástico do hexanal, a contribuição ao aroma da nota maçã verde no suco prensado deve ter aumentado.

TABELA 1. Efeito do processamento na área e na porcentagem relativa dos compostos voláteis da maçã Fuji (safra 94).

\begin{tabular}{|c|c|c|c|c|c|c|c|c|c|}
\hline \multirow[t]{2}{*}{ Píco } & \multirow[t]{2}{*}{ Composto } & \multicolumn{2}{|c|}{ Fruta } & \multicolumn{2}{|c|}{ Suco Prensado } & \multicolumn{2}{|c|}{ Suco Clarificado } & \multicolumn{2}{|c|}{ Sum Pasteurizado } \\
\hline & & Área $^{1}$ & $\%$ Área $^{2}$ & Área $^{1}$ & \% Área ${ }^{2}$ & Área ${ }^{1}$ & $\%$ Área $^{2}$ & Área ${ }^{1}$ & $\%$ Área $^{2}$ \\
\hline 4 & butanoato de metila ${ }^{3}$ & & & & & & & & \\
\hline 6 & acetato de isobutila ${ }^{3}$ & & & & & & & & \\
\hline 7 & 2-metil butanoato de metila & & & & & & & & \\
\hline 8 & hexanal & 347 & 2,5 & 9231 & 41,1 & 9913 & 44,2 & 1358 & 39,7 \\
\hline 9 & butanoato de etila & 335 & 2,5 & $*$ & * & $*$ & * & 107 & 3,1 \\
\hline 10 & propion ato de propila & 76 & 0,6 & 96 & 0,5 & 105 & 0,5 & 16 & 0,5 \\
\hline 11 & acetato de butila & 2196 & 16,0 & 3060 & 14,2 & 3311 & 14,9 & 474 & 13,5 \\
\hline 14 & 2-metil butanoato de etila & 150 & 1,1 & 254 & 1,3 & 271 & 1,1 & 36 & 1,1 \\
\hline 15 & NI & 75 & 0,5 & 2247 & 8,4 & 1520 & 6,7 & 325 & 9,3 \\
\hline 16 & NI & 75 & 0,6 & 360 & 1,3 & 147 & 0,6 & 59 & 1,7 \\
\hline 17 & acetato de 2 -metil butila & 2542 & 18,6 & 2738 & 13,0 & 2899 & 13,2 & 475 & 13,4 \\
\hline 18 & butanoato de propila & 247 & 1,8 & 381 & 1,9 & 472 & 2,1 & 71 & 2,0 \\
\hline 19 & valerato de etila & $\mathrm{tr}$ & $\operatorname{tr}$ & $\mathrm{tr}$ & $\mathrm{tr}$ & $\mathrm{tr}$ & tr & tr & tr \\
\hline 20 & propionato de butila & 228 & 1,7 & 176 & 0,8 & 196 & 0,9 & 29 & 0,8 \\
\hline 21 & acetato de amila & 109 & 0,8 & 122 & 0,6 & 128 & 0,6 & 18 & 0,5 \\
\hline 22 & hexanoato de metila & 48 & 0,4 & $\mathrm{tr}$ & $\mathrm{tr}$ & $\mathrm{tr}$ & tr & tr & $\mathrm{tr}$ \\
\hline 24 & 2-metil butanoato de propila & 111 & 0,8 & 98 & 0,5 & 129 & 0,6 & 22 & 0,6 \\
\hline 27 & NI & 23 & 0,2 & tr & tr & $\mathrm{tr}$ & tr & tr & tr \\
\hline 28 & NI & tr & $\operatorname{tr}$ & tr-17 & $\mathrm{tr}-0,1$ & 38 & 0,2 & tr & tr \\
\hline 30 & butanoato de butila & 302 & 2,2 & 364 & 1,7 & 490 & 2,2 & 71 & 2,0 \\
\hline 31 & hexanoato de etila & 90 & 0,7 & 94 & 0,4 & 106 & 0,5 & 15 & 0,4 \\
\hline 34 & acetato de hexila & 1503 & 11,0 & 1479 & 6,5 & 1529 & 7,0 & 206 & 5,8 \\
\hline 35 & acetato de ciclo hexila & 55 & 0,4 & 57 & 0,2 & 61 & 0,3 & tr & tr \\
\hline 36 & NI & tr-27 & $\mathrm{tr}-0,2$ & tr & tr & 35 & 0,2 & $\mathrm{tr}-10$ & $\mathrm{tr}-0,3$ \\
\hline 37 & 2-metil butanoato de butila & 206 & 1,5 & 123 & 0,6 & 167 & 0,7 & 28 & 0,8 \\
\hline 43 & hexanoato de propila & 37 & 0,3 & 31 & 0,2 & 49 & 0,2 & $\operatorname{tr}$ & $\operatorname{tr}$ \\
\hline 44 & NI & 19 & 0,1 & $\operatorname{tr}-16$ & $\mathrm{tr}-0,1$ & 37 & 0,2 & tr & tr \\
\hline 45 & propanoato de hexila & 80 & 0,6 & tr & tr & tr & tr & tr & tr \\
\hline 47 & 2-metil buta noato de amila & tr & $\mathrm{tr}$ & tr & tr & tr & tr & tr & tr \\
\hline 49 & NI & 36 & 0,3 & nd & nd & $\operatorname{tr}$ & $\operatorname{tr}$ & $\mathrm{tr}-12$ & tr $-0,4$ \\
\hline 52 & hexanoato de butila & 149 & 1,1 & 223 & 1,1 & 283 & 1,3 & 44 & 1,3 \\
\hline 53 & butanoato de hexila & 144 & 1,1 & $*$ & $*$ & $*$ & $*$ & $*$ & $*$ \\
\hline 57 & 2-metil butanoato de hexila & 312 & 2,3 & 136 & 0,8 & 91 & 0,4 & 19 & 0,5 \\
\hline 58 & hexanoato de isoamila & $\operatorname{tr}$ & $\operatorname{tr}$ & $\operatorname{tr}$ & $\operatorname{tr}$ & tr & $\operatorname{tr}$ & tr & $\operatorname{tr}$ \\
\hline 63 & NI & nd-107 & nd- $-0,9$ & nd & nd & nd & nd & nd & nd \\
\hline 64 & $\mathrm{NI}$ & nd-31 & nd- $-0,2$ & nd & nd & nd & nd & nd & nd \\
\hline 66 & hexanoato de hexila & 219 & 1,6 & 42 & 0,2 & $\operatorname{tr}$ & tr & tr -15 & $\mathrm{tr}-0,4$ \\
\hline 67 & NI & 46 & 0,3 & nd & nd & nd & nd & nd & nd \\
\hline 69 & octanoato de isoamila & $\operatorname{tr}$ & $\operatorname{tr}$ & nd & nd & tr & tr & nd & nd \\
\hline 70 & NI & $\begin{array}{c}\text { nd- } \\
2130\end{array}$ & nd-17,1 & nd & nd & tr & tr & nd & nd \\
\hline 74 & $\alpha$-farneseno & 2870 & 20,9 & 490 & 2,6 & 98 & 0,4 & tr & $\operatorname{tr}$ \\
\hline 75 & NI & 38 & 0,3 & $\operatorname{tr}-122$ & nd- 0,3 & nd & nd & $\operatorname{tr}$ & tr \\
\hline 79 & NI & tr- -23 & $\mathrm{tr}-0,2$ & tr- -83 & $\mathrm{tr}-0,2$ & $\operatorname{tr}-12$ & tr $-0,1$ & tr- -52 & $\operatorname{tr}-1,3$ \\
\hline 80 & NI & $\mathrm{tr}-21$ & $\mathrm{tr}-0,2$ & $\operatorname{tr}$ & tr & tr & tr & nd-31 & nd- $-0,8$ \\
\hline 83 & NI & 18 & 0,1 & 54 & 0,3 & tr & tr & tr- -94 & tr- 2,4 \\
\hline 84 & NI & $\operatorname{tr}$ & tr & tr- -22 & tr- $-0,1$ & tr & tr & tr -32 & $\operatorname{tr}-0,8$ \\
\hline
\end{tabular}

${ }^{1}$ Área: média ou amplitude de área de 3 amostras analisadas;

Área: média ou amplitude da porcentagem relativa de área de 3 amostras analisadas ${ }^{3}$ compostos volāteis na região do "hump" do solvente; NI: composto não identificado; nd: pico não detectado tr: pico presente com \% < 0,05 ;
*: pico não separado

A clarificação do suco foi a etapa que menos causou mudanças na composição dos voláteis. O hexanal continuou sendo o componente majoritário, com 44\%. O 2-metil butanoato de hexila diminuiu levemente de $0,8 \%$ para $0,4 \%$ e o $\alpha$-farneseno diminuiu ainda mais em relação ao suco prensado, de $3 \%$ para 0,4\%. Como um composto terpênico, o $\alpha$-farneseno é altamente instável [11].

A pasteurização do suco efetuada a $80^{\circ} \mathrm{C}$ por 20 minutos, foi a etapa do processamento que engendrou as mudanças mais drásticas na composição dos voláteis, como esperado. Ocorreu a perda total do éster octanoato de isoamila e de 15 componentes não identificados, além de perda parcial do hexanal, do $\alpha$-farneseno e dos ésteres, com exceção de hexanoato de hexila, que aumentou ligeiramente.

Apesar desta perda parcial, o hexanal continuou sendo o componente majoritário (40\%). Sua área diminuiu muito (de 9900 para 1300), evidenciando a grande 
perda desse componente. Alguns compostos não identificados aumentaram ligeiramente suas áreas.

Deve ser ressaltado que os compostos mais abundantes foram sempre os mesmos, em todos os sucos obtidos. Estes compostos majoritários foram hexanal, acetato de butila, acetato de 2-metil butila, um composto não identificado (pico 15) e acetato de hexila. Em ordem decrescente de porcentagem relativa, mantiveram-se aproximadamente com 40\%, 14\%, 13\%, 8\% e $6 \%$, respectivamente, em todos os sucos (prensado, clarificado e pasteurizado).

KAKIUCHI et al. [8] estudando as modificações nos compostos voláteis da maçã Fuji, observaram de uma maneira geral, a diminuição de todas as classes quimicas e a perda total do hidrocarboneto $\alpha$-farneseno no suco pasteurizado, mesmo quando o tratamento térmico foi realizado rapidamente à alta temperatura $\left(93^{\circ} \mathrm{C}\right.$ por 30 segundos). Neste estudo, também foi observado um aumento do hexanal no suco pasteurizado, que duplicou a sua concentração (ppm) em relação à fruta fresca. De acordo com os autores, o produto final apresentou qualidade sensorial inferior e esta modificação do sabor resultou principalmente da diminuição no teor de aldeídos, ésteres e álcoois. No presente trabalho, os ésteres foram a classe química majoritária e o aldeído hexanal se tornou o componente majoritário após a prensagem e, apesar de ter diminuído durante a pasteurização, ainda apresentou uma porcentagem relativa maior em relação à fruta fresca.

Ésteres (acetatos, propanoatos, 2-metil butanoatos e butanoatos) e aldeídos $\mathrm{C}_{6}$ são considerados importantes para o aroma de maçãs [3, 11]. Portanto, a diminuição da área desses compostos após a pasteurização acarreta uma perda de notas aromáticas no produto final.

A etapa de pasteurização é utilizada no processamento de bebidas para aumentar a vida de prateleira e garantir a segurança microbiológica do produto. Porém, o uso do calor por tempo prolongado acarretou perdas dos compostos voláteis em grande extensão (Figura 1). Outras técnicas viáveis economicamente podem ser utilizadas para minimizar as perdas de aroma durante o processamento, tais como técnicas de recuperação de aroma por parcial condensação, pervaporação, adsorção, destilação e evaporação [9], visando uma melhora na qualidade de aroma do suco clarificado de maçãs.

\section{4 - CONCLUSÕES}

- A classe química predominante de compostos voláteis da maçã Fuji foi a dos ésteres, sendo os compostos majoritários o $\alpha$-farneseno, acetato de 2-metil butila, acetato de butila, acetato de hexila.

- $\quad \mathrm{Na}$ prensagem o aldeído hexanal com $2 \%$ de porcentagem relativa na fruta fresca, se tornou o componente majoritário (até 40\%), enquanto $\alpha$ farneseno, o mais abundante na fruta fresca, diminuiu marcantemente para até $2 \%$, nas amostras relativas à safra de 1994 .
- A etapa de clarificação foi a que menos causou modificações na composição de voláteis mantendo o aldeído como componente majoritário.

- A pasteurização a $80^{\circ} \mathrm{C}$ por 20 minutos foi a etapa do processamento que engendrou as maiores perdas na composição dos voláteis, perda total do éster octanoato de isoamila e de mais 15 compostos não identificados.

- Os compostos voláteis majoritários (acetato de butila, acetato de 2-metil butila, acetato de hexila e um composto não identificado) se mantiveram após a prensagem e em todas as etapas do processamento.

\section{5 - REFERÊNCIAS BIBLIOGRÁFICAS}

[1] ABPM - Associação Brasileira dos Produtores de Maçã. Acessado em 12/11. http://www.abpm.org.br, 2002

[2] Di CESARE L.F., VITAli S., SCOTTO P. Control of influence of technological treatments on the aroma profile during fruit juice preparation. Fruit Processing, v. 1, n. 5, p. 68-71, 1991.

[3] DIMICK, P.S., HORKIN, J.C. Review of apple flavor state of the art. CRC Crit. Rev. Food Sci. Nutr., v. 18, n. 4, p. 387-409, 1983.

[4] FRANCO, M.R.B., RODRIGUEZ-AMAYA, D.B. Trapping of soursop (Annona muricata) juice volatiles on Porapak Q by suction. J. Sci. Food Agric., v. 34, n. 3, p. 293-299, 1983.

[5] JANZANTTI, N.S. I. Composição de voláteis de maçãs (Malus domestica) cultivar Fuji. II. Efeito do processamento e do armazenamento na composição de voláteis de suco clarificado de maçã Fuji, 1996, p. 180. Dissertação (Mestrado em Ciência de Alimentos). Faculdade de Engenharia de Alimentos, Universidade Estadual de Campinas (UNICAMP), Campinas, Brasil.

[6] JANZANTTI, N.S., FRANCO M.R.B, LANÇAS F.M. Identificação de Compostos Voláteis de Maçãs (Malus Domestica) Cultivar Fuji por Cromatografia Gasosa - Espectrometria de Massas. Ciênc. Tecnol. Aliment., v. 20, n. 2, p. 164-171, 2000.

[7] JENNINGS, W., SHIBAMOTO T. Qualitative analysis of flavor and fragrance volatiles by glass capillary gas chromatography. New York: Academic Press, 1980.

[8] KAKIUCHI, N., MORIGUCHI, S., ICHIMURAM N., KATOM Y., BANBA, Y. Changes in the composition and amounts of volatiles compounds of apple juice associated with thermal processing. Nippon Shokuhin Kogyo Gakkaishi, v. 34, n. 2, p. 115122, 1987.

[9] KARLsSON, H.O.E, TRÄGÅRDH, G. Aroma Recovery During Beverage Processing. Journal of Food Engineering, v. 34, n. 2, p. 159-178, 1997.

[10] MERORY, J. Food Flavorings. Connecticut: The Avi Pusblishing Company, Inc. p. 3-59, 1968.

[11] PAILLARD, N.M. The Flavour of Apples, Pears and Quinces. In: Morton ID, Macleod, AJ, editors. The Favours of Fruits. New York: Elsevier, Inc. p. 1-42, 1990.

[12] PÉREDI, K., VÁMOS-VIGYAXÓL, KISS-KUTZ, N. Flavor losses in apple juice manufacture. Die Nahrung, v. 25, n. 6, p. 573-582, 1981.

[13] SATAQUE, E.Y., WOSIACKI, G. Caracterização da polifenoloxidase da maçã (Malus domestica, var Gala). Arq. Biol. Tecnol., v. 30, n. 2, p. 287-299, 1987. 
[14] STENHAGEN, F., ABRAHAMsson, S., MCLAFFERTy, F.W. 1974. Registry of Mass Spectral Data. New York: John Willey \& Son, v. 1 e 2, 1974.

[15] WOSIACKI G., KAMIKOGA, A.T.M., SATAQUE, E.Y., CÉSAR, E.O. Características de qualidade de sucos despectinizados de maçãs. Semina Ci. Agr., v. 13, n. 1, p. 7-14, 1992.

[16] WOSIACKI, G., NAMiUChI, N.N., CEREBElli, M.I., SATAQUE, E.Y., SINCHIERI, V.L., OLIVEIRA, T.C., CESAR EO. Estabilidade do suco clarificado de maçãs. Parte I-Processo de obtenção do suco de maçãs. Arq. Biol. Tecnol., v. 32, 4, p. 775-786, 1989.
[17] WOSIACKI, G., SINCHIERI, V.L., CEREBELLI, M.I., SATAQUE, E.Y., NAMIUCHI, N.N., CESAR, E.O. Avaliação do uso da maçã nacional (Malus domestica) para fins industriais. I - Características de qualidade dos sucos das variedades Fuji, Gala e Golden Delicious.

B. Soc. Bras. Ciênc. Tecnol. Aliment., v. 21, n. 2, p. 65-78, 1987.

\section{6 - AGRADECIMENTOS}

À FAPESP pelo auxilio financeiro, processo $n^{\circ}$ 94/ 2548-0, ao CNPq e FAEP/UNICAMP pelas bolsas concedidas para a realização deste trabalho. 